\title{
LA RESPONSABILIDAD SOCIAL, EOLOELÉCTRICAS Y ADMINISTRACIONES PÚBLICAS: LOS CASOS DE ELÉCTRICA DEL VALLE DE MÉXICO Y EL AYUNTAMIENTO DE ASUNCIÓN IXTALTEPEC, OAXACA
}

\section{Social responsibility, electricity and public administrations: the cases of Eléc- trica del Valle de México and the Municipality of Asunción Ixtaltepec, Oaxaca}

\author{
Jorge Martín Cordero Torres \\ Profesor Investigador titular "A" adscrito al Departamento de Administración Pública de la Universidad del Istmo, \\ campus Ixtepec, Oaxaca; México. ORCID: http://orcid.org/0000-0002-8938-4017ORCID: http://orcid.org/0000- \\ 0002-8938-4017
}

Recibido: 27/10/2018 • Aprobado: 3/11/2018

Cómo citar: Cordero Torres, J. (2018). La responsabilidad social, eoloeléctricas y administraciones públicas: los casos de Eléctrica en el Valle de México y el Ayuntamiento de Asunción Ixtaltepec, Oaxaca. Ciencia y Sociedad, 43(4), 37-49. doi: http://dx.doi.org/10.22206/cys.2018.v43i4.pp37-49

\section{Resumen}

El presente trabajo está basado en la responsabilidad social, un tema de gran importancia para los diversos actores económicos, empresas, gobiernos locales y sociedad. De ahí que varios organismos internacionales hayan propuesto lineamientos para regular el comportamiento corporativo. Así también, la responsabilidad social de las administraciones públicas tiene doble perspectiva, hacia la promoción y hacia el interior de las mismas. Últimamente las administraciones públicas han tenido una pérdida de la confianza ciudadana. En este estudio se da cuenta de la percepción y postura de la empresa eólica Eléctrica del Valle de México Sociedad de Responsabilidad Limitada y la administración municipal de Asunción Ixtaltepec, Oaxaca; en torno a la responsabilidad social empresarial. Para la administración municipal se utiliza como marco de referencia la metodología de la Agenda desde lo local, esta permite identificar las condiciones actuales y a partir de ello, alcanzar condiciones mínimas para promover el desarrollo.

Palabras clave: Responsabilidad social empresarial; políticas públicas; administración municipal; Agenda desde lo local; empresas eólicas.

\begin{abstract}
This paper examines diverse economic participants, business, local government and society at large in light of the very important matter of social responsibility. Out of concern for socially responsible standards, various international organizations have proposed guidelines to regulate corporate behavior. Public administrators have a dual perspective on social responsibility. One focuses on public promotion while the other is concerned with their organizations internal matters. Lately, citizens have lost confidence in public administrative agencies. This study examines Eólica Eléctrica del Valle de México Limited Liability Company and a wind energy company, and the municipal administration of Asunción Ixtaltepec, Oaxaca in terms of their positions and perspectives on social responsibility in business. Local-level agenda methodology is used as a frame of reference for municipal administration, and this facilitates the identification of current conditions as a means of attaining a minimal threshold for promoting development.
\end{abstract}

Keywords: Social responsibility in business; public policy; municipal administration; local-level agenda methodology; wind energy companies. 


\section{Introducción}

El tema a tratar y objeto de estudio es la Responsabilidad Social Empresarial (RSE) en una empresa eólica, Eléctrica del Valle de México, y de una administración local como es el ayuntamiento de Asunción Ixtaltepec, en el estado de Oaxaca, en el sureste mexicano. El primero de abril de 2010, entró en operación la central eólica instalada en los ejidos "La Mata" y "La Ventosa" en la región del Istmo en el estado de Oaxaca. La primer central pertenece a Eléctrica del Valle de México (EVM) y es operada por ENXCO Servicios, ambas empresas subsidiarias de EDF (Electricité de France, Energies nouvelles). La central tiene una capacidad instalada de 67.5 $\mathrm{MW}^{1}$, que consta de 27 aerogeneradores marca Clipper C89, de 2.5 MW cada uno. En las reformas del sector energético, se ha recomendado la incorporación de la energía renovable como elemento central. El gobierno se ha comprometido a impulsar la inversión privada en la generación, distribución y transmisión de energía.

Ante las amenazas del cambio climático y la seguridad energética, el gobierno apuesta por la transición energética. Esta consiste en un cambio de enfoque en el sector energético. Un proceso en el cual se genere un mejor aprovechamiento de los combustibles fósiles y se desarrolle y fomente el uso de energías renovables, con el fin de diversificar las fuentes primarias de energía y aminorar el impacto al medio ambiente disminuyendo las emisiones de gases de efecto invernadero causadas por el uso de combustibles fósiles, los que actualmente son la principal fuente de energía. Según lo dicho, la energía eólica representa una fuente energética limpia, de una fuente natural, renovable y no contaminante. Los actuales generadores son capaces de producir electricidad a precios competitivos. En México se han identificado zonas con potencial de explotación eólica para la generación eléctrica,

1. MW, Megavatios, igual a un millón de vatios. entre ellas destacan la región del Istmo en el estado de Oaxaca, La Rumorosa en el estado de Baja California, así como en los estados de Zacatecas, Hidalgo, Veracruz, Sinaloa y en la península de Yucatán (tech4CDM, 2009).

A nivel de entidad federativa, el estado de Oaxaca se divide en ocho regiones y 570 municipios, de ellos 418 bajo el régimen de usos y costumbres y 152 en el régimen de partidos políticos. La región del Istmo oaxaqueño está compuesta por dos Distritos, el Distrito de Juchitán y el Distrito de Tehuantepec, y los integran aproximadamente 44 municipios.

También debe señalarse que el presente trabajo se inscribe dentro del proyecto denominado "Estudio Socioeconómico y Jurídico-Institucional en Perspectiva Comparada sobre el Desarrollo de Energía Eólica en la Región Istmo-Costa: los casos de Ixtaltepec; Oaxaca y Arriaga, Chiapas", principalmente en la dimensión social, en el apartado de responsabilidad social, que lleva a cabo el Cuerpo de Políticas Públicas de la Unistmo-CA-4.

Con relación a la Responsabilidad Social Empresarial, se trata de identificar las posturas y la vinculación, si existe, entre una empresa eólica y una administración municipal. En este propósito, se describe la evolución y se dan algunas definiciones de RSE, así como su institucionalización. De igual forma, la Responsabilidad Social de las administraciones públicas, un diagnóstico y un apartado de conclusiones.

\section{Evolución y definición de la responsabilidad social}

Los orígenes de la responsabilidad social datan de fines del siglo XIX, pero es durante el siglo XX cuando el concepto se generaliza. Según Teixidó, Chavarri y Castro (2002), la RSE surge por una parte, en un contexto de debilitamiento del Estado y por otra, por la crisis de confianza frente a las actividades de 
la empresa y presión de parte de las organizaciones de la sociedad civil. Este escenario impulsó a las empresas "hacia un proceso de relegitimación social, donde, las demandas por una mejor calidad de vida, cuidado del medio ambiente, participación en el desarrollo social de la comunidad y en el país, son temáticas que pasan a convivir con la ganancia inmediata" (Teixidó et al., 2002, p. 5).

Cabe destacar que las primeras nociones de RSE, se centraban en actividades filantrópicas, basadas en la caridad (Organización Internacional de Normalización [ISO], 2010).

Con la apertura comercial, los actores globales asumen nuevas funciones. Empresas trasnacionales han adquirido nuevos patrones de conducta, identificadas con la filosofía de la Responsabilidad Social Empresarial. México aparece en el contexto latinoamericano con avances limitados. La RSE ha sido promovida por organizaciones multinacionales y su difusión al resto de las empresas aún es parcial. Además, hasta hace poco, el tema de la responsabilidad de las empresas aparecía dentro del ámbito de la filantropía (Martínez, 2007).

$\mathrm{Al}$ respecto, el Centro Mexicano para la Filantropía, Asociación Civil (CEMEFI, A. C.) y la Alianza para la Responsabilidad Social Empresarial (AliaRSE), han sido las instancias encargadas de entregar los distintivos Empresa Socialmente Responsable (ESR) a empresas que demuestran tener gestiones éticas.

Al ser evidente que la filantropía corporativa no era suficiente respuesta a las demandas de la sociedad, se va transitando hacia una mirada más estratégica de la responsabilidad social empresarial. Cada vez, se hace indudable que las empresas generan impacto a través de sus operaciones y que deben reducirse los efectos negativos y potenciar los positivos. Porter y Kramer señalan que el sector privado y la sociedad no son entes contrapuestos, sino que son interdependientes y, más aún, "las corporaciones exitosas necesitan de una sociedad sana y una sociedad sana necesita de empresas exitosas" (Porter y Kramer, 2006, p. 7).

Derivado de la exposición anterior, la RSE se puede entender como aquella "responsabilidad de una organización ante los impactos que sus decisiones y actividades (productos, servicios y procesos) ocasionan en la sociedad y el medio ambiente, mediante un comportamiento ético y transparente, que contribuya al desarrollo sostenible, tome en consideración las expectativas de sus partes interesadas; cumpla con la legislación aplicable y esté integrada en toda la organización" (ISO, 2010, p. 4).

Los grupos de interés o stakeholders son elementos esenciales en la teoría de la responsabilidad social. El término grupos de interés se usó por primera vez en 1963, en función de la supervivencia corporativa; luego se incorporó a la comunidad local y a la sociedad en general, incluyendo a directivos, trabajadores, contratistas, proveedores, clientes, sindicatos y competidores. Freeman define a los grupos de interés "como grupos o individuos que pueden verse afectados por las operaciones de la empresa" (Freeman, 1984; citado por Balaguer, Hernández y Muñoz, 2007, p. 18).

De acuerdo con el Consejo Nacional de la Cultura y las Artes (CNCA, 2013), otro concepto fundamental para comprender la visión actual de la RSE y que, de acuerdo con los autores, refuerza el distanciamiento del concepto de filantropía, es el de valor compartido, el cual es entendido como "políticas y prácticas operacionales que mejoran la competitividad de una empresa a la vez que ayudan a mejorar las condiciones económicas y sociales en las comunidades donde opera. La creación de valor compartido se enfoca en identificar y expandir las conexiones entre los progresos económico y social" (Porter y Kramer, 2011, citado por CNCA, 2013, p. 6). El sustento del concepto, es que las empresas pueden crear valor económico creando valor 
social y esto se logra mediante: nuevos productos y mercados, redefiniendo la productividad en la cadena de valor y creando clusters $^{2}$ locales (Vidal, 2011).

\section{La Responsabilidad Social Empresarial y su institucionalización}

Dentro de los documentos que abordan de manera oficial y a nivel internacional el concepto de RSE, se encuentra el Libro Verde de la Responsabilidad Social Empresarial, impulsado por la Comunidad Europea y en él se plantea que las acciones de las empresas deben trascender el cumplimiento normativo e invertir en ámbitos sociales y ambientales.

Por otro lado, en el año 2000, a iniciativa de la Organización de las Naciones Unidas se creó el Pacto Global, convocando a distintas compañías en el mundo para integrar en su operación el respeto y la promoción de diez principios universales relacionados con los derechos humanos, las relaciones laborales, el medio ambiente y la anticorrupción.

En la misma década, se consolidó el Global Reporting Iniciative (GRI), organización dedicada al desarrollo de marcos para la elaboración de Reportes de Sostenibilidad, documentos que dan cuenta del desempeño de las organizaciones en materia económica, social y ambiental. Pretendía que para el 2015 todas las grandes y medianas empresas de países de la Organización para la Cooperación y el Desarrollo Económicos (OCDE) y las economías emergentes, deban reportar o explicar por qué no lo hacen. El Global Reporting Iniciative (GRI) es una organización cuyo fin es impulsar la elaboración de memorias de sostenibilidad en todo tipo de organizaciones, éstas pueden medir y dar a conocer su desempeño económico, ambiental y social (Intedya, 2018).

2. Los clusters, entendidos como un conjunto de sectores productivos competitivos interrelacionados.
El GRI determina cuatro principios básicos para el desarrollo de los reportes: participación de los grupos de interés (identificar los grupos de interés y conocer sus intereses y expectativas); materialidad (informar sobre aspectos e indicadores que reflejen los impactos significativos de la organización o aquellos que podrían ejercer una influencia sustancias en los grupos de interés); contexto de sostenibilidad (evaluar la contribución de la organización a las tendencias medioambientales y sociales); y exhaustividad (cobertura de los aspectos definidos como materiales). Actualmente son muchas las empresas que elaboran reportes de sostenibilidad como una forma de ser transparentes con sus grupos de interés y dar respuesta a sus expectativas.

La norma AA 1,000, es un estándar que complementa el GRI; esta norma fue elaborada por el Instituto Accountability, que trata de orientar a las organizaciones sobre cómo incorporar a los grupos de interés para identificar, comprender y responder a los temas y preocupaciones, involucrándolas en la toma de decisión de la empresa. Los principios que la orientan son: Inclusividad, compromiso de ser responsable con aquellos sobre los cuales la organización genera un impacto y con los que generan un impacto en la empresa; Relevancia, determina la importancia y priorización que los diversos temas tienen no solo para la organización sino también para sus grupos de interés; y Capacidad de respuesta, que son decisiones, acciones o lazos de comunicación que la organización realiza o mantiene con los grupos de interés que afectan su desempeño en materia de sostenibilidad.

Resulta oportuno señalar que "la norma AA1000AS (2003), reemplazó la información sobre aseguramiento proporcionada por la norma marco AA1000 publicada en 1999" (Accountability, 2008: 5). La versión 2008 de la norma de aseguramiento AA1000AS es la segunda edición de la Norma de Aseguramiento Accountability (Accountability, 
2008). Con referencia a lo anterior, la norma AA1000 consta de tres normas:

1. AA1000APS (2008) Principios de
Accountability

2. AA1000AS (2008) Norma deAseguramiento,

3. AA1000SES (2005) Norma de compromiso con los grupos de interés.

Posteriormente, en el año 2010 se publicó la norma ISO 26000, norma internacional sobre responsabilidad social cuyo objetivo es ayudar a las organizaciones a contribuir al desarrollo sostenible, esta norma no tiene propósitos de certificación, regulatorio o contractual, ni es una norma de gestión, es un esfuerzo por consolidar estándares en materia de RSE y entregar orientaciones generales para las organizaciones. Se integra por siete materias fundamentales: gobernanza de la organización, prácticas laborales, derechos humanos, prácticas justas de operación, asuntos de consumidor, medio ambiente, participación activa y desarrollo de la comunidad.

Junto con la institucionalización, que es un proceso a través del cual una empresa $u$ organismo pasa de ser un negocio que opera bajo la visión y dirección de sus fundadores, a una empresa que adquiere vida propia en diferentes aspectos, la responsabilidad social empresarial ha formalizado su gestión al interior de las empresas. Aunque las razones para su aplicación inicial pueden haber estado ligadas más a convicciones personales de los dueños o ejecutivos de las organizaciones, se ha acordado a que sí ésta es gestionada en forma estratégica, puede generar beneficios para la empresa.

\section{La Responsabilidad Social en las Administraciones Públicas (RSA)}

A continuación, se aportan algunas definiciones de responsabilidad social aplicadas a las administraciones públicas por diversos autores. Para Soria:
Se puede entender por responsabilidad social pública como el nuevo resultado derivado de la gestión "explícita" de política pública del Estado, orientada a lograr una sociedad más equitativa e igualitaria, siendo su vehículo la reconstrucción de la idea de "bien común" a través de la cultura de lo solidario (Soria, 2014, p.6).

Por otro lado, Cueto señala que:

La responsabilidad corporativa pública es un compromiso voluntario, más allá del cumplimiento de la legislación propia del nivel de competencia, en torno a la atención directa $y / o$ indirecta de necesidades de los grupos de interés, a través de un gobierno y administración pública transparente $y$ responsable en sus diferentes niveles de gestión, que contribuyan a multiplicar la sostenibilidad colectiva, tanto económica, como social y medioambiental. ¿Para qué sirve? La gestión de la responsabilidad social por el sector público es un "medio" o instrumento cuya misión principal es hacer efectivo el fin o compromiso global de desarrollo sostenible global (económicosocial-ambiental) desde los gobiernos y administraciones públicas, de una forma compartida con entidades del sector privado y otros grupos de interés. (Cueto, 2017, p. 1)

Asimismo, la Administración General del Estado (AGE) del Ministerio de Hacienda y Administraciones Públicas, en su informe sobre prácticas socialmente responsables publicado en el 2012, señala que:

Es el conjunto de compromisos de diverso orden, económico, social y medioambiental, adoptado por las organizaciones e instituciones públicas que forman parte de la AGE y que constituyen un valor añadido al cumplimiento de sus obligaciones legales, contribuyendo a la vez al progreso social y 
económico en el marco de un desarrollo sostenible. (AGE, 2012)

De manera semejante, Del Pino define la responsabilidad social organizacional (RSO):

En la medida que los Estados y gobiernos se autoimpongan metas de desarrollo económico, social y ambiental que vayan más allá de sus funciones y del cumplimiento de los requerimientos urgentes y se fortalezcan a sí mismos, generando una cultura de responsabilidad social que tiñe al resto de las instituciones, estarán cumpliendo con el fomento de la RSO. (Del Pino, 2012, p. 4)

Según Canyelles, la vinculación de las administraciones públicas con la Responsabilidad Social Corporativa (RSC) puede concebirse bajo una doble perspectiva, la promoción entre las empresas (RSE), o bien la aplicación interna de la responsabilidad social a las administraciones (RSA) (Canyelles, 2011).

La administración pública en general acusa una pérdida de confianza ciudadana; se le puede atribuir a la percepción de lentitud burocrática en la capacidad de adaptarse y dar respuesta a los nuevos retos, a las práctica opacas de gestión y a los casos de corrupción. Por otro lado, con la RSA como inductor del buen gobierno, aumentan la transparencia en la gestión, fomentan la ética pública, gestionan los impactos sociales, ambientales y económicos y transmiten a la ciudadanía el compromiso de la administración con los valores éticos. En el sector público se observan buenas prácticas de responsabilidad social, pero en aquellas instituciones y empresas cuya forma jurídica se lo facilita.

En palabras de Brugué (2009):

La gobernanza se basa- y en esto coincide con la RSE- en dirigir con la puerta y las ventanas abiertas, tomando en consideración lo que sucede fuera de las paredes de la institución. Asumiendo que no debemos simplificar la complejidad del mundo que nos ha tocado vivir sino, al contrario, incorporarla e integrarla en nuestras actividades de gestión y gobierno. (Brugué, 2009, p. 9)

Aguilar nos dice que gobernanza quiere significar un nuevo proceso directivo:

Gobernanza significa cambio del proceso, modo, patrón de gobierno, que es bien entendido y formulado como el paso de un centro a un sistema de gobierno, en el que se requieren, activan y conjuntan los recursos del poder público, de los mercados y de las redes sociales. (Aguilar, 2010, p. 5)

Es decir, que activen la creación de redes que incorporen la complejidad necesaria para abordar los nuevos retos, con una visión multilateral en la que los diversos actores tomen parte (stakeholders), ya sean públicos, privados o sociales, bajo un principio de corresponsabilidad que solo podrá funcionar y ofrecer resultados si se sabe crear una potente confianza y complicidad mutua.

Dentro del buen gobierno, existe la adopción de compromisos que se vinculan con la RS o cualquier otro concepto afín, ya sea de carácter ético, buenas prácticas y sostenibilidad, como la Agenda 21.

Acciones de la administración en la promoción de la RSE:

- Una administración que desarrolle una legislación específica que contribuya a una mayor responsabilidad social de las empresas.

- Una administración facilitadora o promotora de acciones de RS en las empresas, para que éstas empiecen o continúen con sus acciones de RS.

- Una administración sensibilizadora de la opinión pública para que sea ésta la que 
demande a las empresas en las que trabajan o a las que compran, que actúen de una forma socialmente responsable.

- Una administración líder del proceso de sensibilización siendo una organización de referencia o modelo ejemplar en el que, como organización con empleados y vinculación con la sociedad en la que está inmersa, demuestra a través de su propia actuación que ser responsable con la sociedad, es bueno, tanto para la institución como, por supuesto, para la sociedad.

Aunado a lo anterior, los esfuerzos a nivel internacional que promueven la administración desde la perspectiva de la RS, como lo hacen la Organización Internacional para la Estandarización (ISO) por medio de sistemas que se aplican a la gestión de calidad, como la norma ISO-IWA4 y la norma ISO 26000. En México se denomina NMXCC-25 que establece las directrices para la gestión de la calidad en gobiernos locales. En España, la norma era la UNE-IWA 4:2006, actualmente es la UNE 66182:2016 "Guía para la evaluación integral del gobierno municipal y el desarrollo como ciudad inteligente" (Asociación Española de Normalización y Certificación (AENOR), 2016).

Para México, existe la experiencia de la Secretaría de Gobernación (SG) de impulsar, a través del Instituto Nacional para el Federalismo y el Desarrollo Municipal (INAFED), la Agenda Desde lo Local (ADL), que es un programa y una metodología basada en las premisas de la Agenda Local 21 de la Organización de Naciones Unidas (ONU). Su objetivo es la de promover el desarrollo integral de los municipios, fortalecer sus capacidades de gestión, fomentar el ejercicio de la planeación estratégica en los gobiernos locales y contribuir a la identificación de áreas de oportunidad para generar acciones que les permita alcanzar condiciones mínimas de desarrollo (INAFED-SG, 2012).

\section{Materiales y métodos}

Para dar cuenta de la percepción y postura con respecto a la RSE, nuestro caso de estudio es la eoloeléctrica "Eléctrica del Valle de México" y la administración del Municipio de Asunción Ixtaltepec, Oaxaca; lugar donde se encuentra ubicada dicha empresa. Se aplicaron instrumentos para conocer las estrategias de RSE y también se recurrió a diversas fuentes como las páginas web de las compañías.

Para la administración local, como marco de referencia se utilizó la metodología Agenda Desde lo Local y la encuesta aplicada fue la propuesta por López (2012). La Agenda es un programa del gobierno federal para el desarrollo integral de los municipios. Los indicadores utilizados son parte de los componentes de la Agenda. Los instrumentos fueron aplicados a diferentes funcionarios de la administración pública local que corresponde a cada componente que lo integra:

1. Desarrollo institucional para un buen gobierno; 2. Desarrollo económico sostenible, 3. Desarrollo social sostenible, y 4. Desarrollo ambiental sustentable (ver figura 1). 
Figura 1 Componentes de la Agenda Desde lo local

\section{AGENDA DESDE LO LOCAL}

Descentralización Estratégica para el Desarrollo de lo Local

\section{VERDE=Logros Aceptables de Calidad Local}

AMARILLO=Prácticas Municipales debajo de lo Aceptable

ROJO=Prácticas Municipales Inaceptables

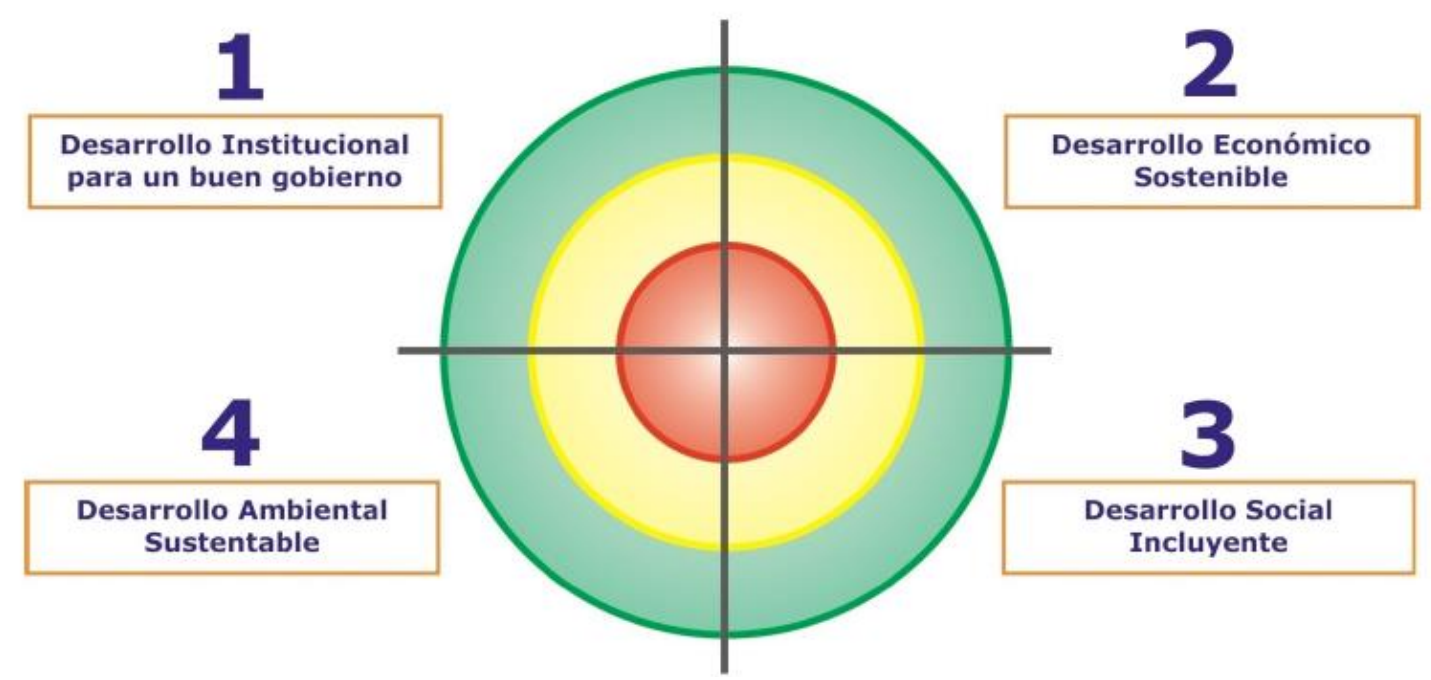

Fuente: tomado de Agenda Desde lo Local (INAFED, 2012).

La encuesta se aplicó a los responsables de las siguientes áreas involucradas en los cuadrantes:

\begin{tabular}{ll}
\hline \multicolumn{1}{c}{ Áreas sugeridas } & \multicolumn{1}{c}{ Órganos municipales } \\
\hline Administración & Presidente municipal; Secretario del ayuntamiento \\
Tesorería & Tesorería \\
Jurídico & Sindicatura \\
Turismo & Regiduría Desarrollo económico \\
Desarrollo agropecuario & Regiduría Desarrollo económico, Reg. Des. Agropecuario. \\
Desarrollo urbano & Regidurías de Planeación; de Ecología; de Transporte. \\
Obras Públicas & Regiduría de Obras Públicas \\
Desarrollo Social & DIF Municipal \\
\hline
\end{tabular}




\section{Resultados}

\section{Responsabilidad Social en las Administraciones (RSA): el Ayuntamiento de Asunción Ixtaltepec, Oaxaca}

Se consultó sobre los indicadores de los cuadrantes de la metodología Agenda Desde lo Local, para identificar las condiciones que no deben dejar de existir en cualquier municipio para un desarrollo integral.

De ellos se obtuvo información esencial para determinar si el municipio cuenta con las condiciones mínimas para alcanzar un desarrollo integral. El semáforo en verde indica logros aceptables de calidad local, el amarillo representa prácticas municipales debajo de lo aceptable y con el rojo se identifican las prácticas municipales inaceptables (Cordero, 2018, p.14).

Siguiendo con la metodología Agenda Desde lo Local y los resultados obtenidos al aplicar las encuestas, la ubicación particular del municipio para los indicadores de los tres componentes: Desarrollo institucional para un buen gobierno, Desarrollo social sostenible y Desarrollo ambiental sustentable, es la de "aceptable", a diferencia del componente de desarrollo económico que se ubica en "no aceptable", por lo tanto se considera que los indicadores se ubican en un nivel de "no aceptable", es decir tienen un nivel bajo o menos desarrollado, y que representan prácticas municipales inaceptables, susceptibles a la mejora o áreas de oportunidad. Lo anterior implicaría la elaboración de un programa de fortalecimiento municipal, este programa debe plantear acciones específicas, así como las dependencias que habrán de llevarlas a cabo; con la finalidad de realizar un ejercicio de planeación estratégica y garantizar las condiciones mínimas aceptables de una administración pública para promover el desarrollo sostenible (Cordero, 2018, p. 14).

Cordero, González y Hernández (2014, p. 46), señalan que los siguientes son temas importantes a considerar en el diseńo de la estrategia de responsabilidad social para la administración:

- Ética, valores y principios

- Derechos humanos y trabajo

- Impacto sobre el medioambiente

- Relaciones con proveedores

- Transparencia y rendición de cuentas

La responsabilidad social de las empresas eólicas: Eléctrica del Valle de México (La Mata, Asunción Ixtaltepec, Oaxaca) ${ }^{3}$

En Aguascalientes La Mata, municipio de Asunción Ixtaltepec, en la región del istmo oaxaqueńo, se encuentra ubicado el parque eólico de la empresa Eléctrica del Valle de México EVM (filial de EDF-Energies Nouvelles, Electricité de France-Energies Nouvelles) con una capacidad reservada de 67.50 MW. e instalada de $50 \mathrm{MW}$. Aguascalientes La Mata es una agencia municipal ubicada a $60 \mathrm{msnm}$, con una población de 813 habitantes.

La central eólica La Mata y La Ventosa pertenecen a EVM y es operada por ENXCO Servicios, ambas empresas subsidiarias de EDF Energies Nouvelles. EDF se encuentra entre los actores clave en el ámbito de generación de electricidad, distribución y suministro en Europa.

3. Con la empresa EVM no se pudo concertar la entrevista y la información se obtuvo únicamente de los sitios web corporativos y de notas periodísticas. 


\section{Cuadro 1. Obras y acciones sociales}

\begin{tabular}{ll}
\hline \multicolumn{1}{c}{ Acciones } & \multicolumn{1}{c}{ Descripción } \\
\hline Pavimentación & $\begin{array}{l}\text { 1,700 metros lineales de las calles } \\
\text { Emiliano Zapata, Miguel Hidalgo, } \\
\text { Mina y Prolongación Juárez }\end{array}$ \\
Construcción del salón & $\begin{array}{l}\text { Telesecundaria "Carlos Altamira- } \\
\text { no" }\end{array}$ \\
de computo & Plaza cívica \\
Techado & Esc. Prim. "Emiliano Zapata" y \\
Rehabilitación de baños & Jardín de Niños "La voz de mi \\
& patria" \\
Taller de costura para & Compra de seis máquinas indus- \\
apoyar a las mujeres & triales \\
\hline
\end{tabular}

Fuente: (Cordero et al., 2014, p. 7).

La inversión de cinco millones de pesos proporcionados por la empresa se tradujo en obras y acciones sociales descritas en el cuadro No. 1

Conceptos indispensables que no considera la empresa:

\begin{tabular}{|c|c|c|}
\hline \multirow[t]{2}{*}{$\begin{array}{l}\text { Nivel de } \\
\text { integración } \\
\text { de la RSE } \\
\text { en la organi- } \\
\text { zación }\end{array}$} & $\begin{array}{l}\text { Estrategia } \\
\text { de RSE }\end{array}$ & $\begin{array}{l}\text { Es un mecanismo para guiar el } \\
\text { negocio de una empresa, desde } \\
\text { la toma de decisiones hasta la } \\
\text { introducción de políticas e in- } \\
\text { dicadores. Tiene la finalidad de } \\
\text { identificar oportunidades, in- } \\
\text { corporando las preocupaciones } \\
\text { y expectativas de los grupos de } \\
\text { interés y manejando externali- } \\
\text { dades para generar ventaja com- } \\
\text { petitiva y garantizar el desem- } \\
\text { peño económico a largo plazo. }\end{array}$ \\
\hline & Política RSE & $\begin{array}{l}\text { Documento o declaración ex- } \\
\text { plícita y pública que resume los } \\
\text { compromisos de una empresa } \\
\text { en materia de RSE. }\end{array}$ \\
\hline
\end{tabular}

\section{Discusión}

Finalmente, la estructura organizativa del ayuntamientodel MunicipiodeAsunción Ixtaltepec,
Oax., debe transformarse para poder estar más cerca de las inquietudes de los ciudadanos, debe formar a un personal motivado, profesionalizado e implicado en RSC para que ayude a conseguir una administración más receptiva, que responda con prontitud y diligencia a nuevas necesidades y obligaciones, facilitando más información y potenciando mayor participación entre los usuarios y los empleados. Se sugiere mejorar las siguientes áreas como: medio ambiente, organización municipal, personal de la administración pública, y relación con ciudadanos. Esto con el fin de cumplir con los papeles de una administración como: regulador, facilitador, colaborador y promotor de la Responsabilidad Social Administrativa. Por su parte, el Banco Mundial establece ciertas funciones del sector público para promover la RSE

\begin{tabular}{|c|c|c|c|}
\hline Obligar & $\begin{array}{l}\text { Legislación de } \\
\text { obligación y } \\
\text { control }\end{array}$ & $\begin{array}{l}\text { Regulación e } \\
\text { inspección }\end{array}$ & $\begin{array}{l}\text { Sanciones e } \\
\text { incentivos } \\
\text { legales y } \\
\text { fiscales }\end{array}$ \\
\hline Facilitar & $\begin{array}{l}\text { Legislación } \\
\text { facilitadora de } \\
\text { actuaciones. } \\
\text { Apoyo finan- } \\
\text { ciero }\end{array}$ & $\begin{array}{l}\text { Creación de } \\
\text { incentivos. } \\
\text { Aumento de } \\
\text { la concienci- } \\
\text { ación }\end{array}$ & $\begin{array}{l}\text { Capac- } \\
\text { itación } \\
\text { Estimu- } \\
\text { lación de } \\
\text { mercados }\end{array}$ \\
\hline Colaborar & $\begin{array}{l}\text { Combinación } \\
\text { de recursos }\end{array}$ & $\begin{array}{l}\text { Implicación } \\
\text { de stakehold- } \\
\text { ers }\end{array}$ & Diálogo \\
\hline Promocionar & Apoyo político & & $\begin{array}{l}\text { Difus } \\
\text { y rece } \\
\text { cimie }\end{array}$ \\
\hline \multicolumn{4}{|c|}{ Fuente: (Lozano, 2005, citado por Gaete, 2009, p.52) } \\
\hline \multicolumn{4}{|c|}{$\begin{array}{l}\text { Por otro lado, Lozano et al. (2005) han identificado } \\
\text { cuatro modelos de actuación gubernamental en } \\
\text { el ámbito del desarrollo de políticas públicas de } \\
\text { promoción de la RSE, donde cada denominación } \\
\text { manifiesta una perspectiva dominante, pero no } \\
\text { excluyente de las demás (Lozano, et al., 2005, p. } \\
58-63 \text { ). }\end{array}$} \\
\hline
\end{tabular}




\begin{tabular}{|c|c|c|}
\hline Modelo & Característica & Países \\
\hline Partenariado $^{4}$ & $\begin{array}{l}\text { Partenariado como estra- } \\
\text { tegia compartida entre } \\
\text { sectores para la resolu- } \\
\text { ción de retos socio-labo- } \\
\text { rales }\end{array}$ & $\begin{array}{l}\text { Dinamarca, Fin- } \\
\text { landia, Países Ba- } \\
\text { jos, Suecia. }\end{array}$ \\
\hline $\begin{array}{l}\text { Empresa en la } \\
\text { comunidad }\end{array}$ & $\begin{array}{l}\text { Políticas de soft inter- } \\
\text { vention para fomentar la } \\
\text { aplicación de la empresa } \\
\text { en los retos de gober- } \\
\text { nanza de la comunidad } \\
\text { (enterpreneurship y vo- } \\
\text { luntariado) }\end{array}$ & $\begin{array}{l}\text { Irlanda, Reino } \\
\text { Unido }\end{array}$ \\
\hline $\begin{array}{l}\text { Sostenibili- } \\
\text { dad y ciuda- } \\
\text { danía }\end{array}$ & $\begin{array}{l}\text { Versión actualizada del } \\
\text { acuerdo social existen- } \\
\text { te e importancia de una } \\
\text { estrategia de desarrollo } \\
\text { sostenible. } \\
\text { Regulador }\end{array}$ & $\begin{array}{l}\text { Alemania, Aus- } \\
\text { tria, Belgica, Lu- } \\
\text { xemburgo. } \\
\text { Francia }\end{array}$ \\
\hline Ágora & $\begin{array}{l}\text { Creación de grupos de } \\
\text { debate en los que partici- } \\
\text { pan los diferentes actores } \\
\text { para proveer el consenso } \\
\text { público sobre RSE. }\end{array}$ & $\begin{array}{l}\text { Espańa, Grecia, } \\
\text { Italia, Portugal. }\end{array}$ \\
\hline
\end{tabular}

Fuente: (Lozano et al., 2005, p. 63).

El gobierno municipal de Asunción Ixtaltepec, se identifica con la denominación de Sostenibilidad y ciudadanía y Ágora, pues hoy en día es de importancia el desarrollo sostenible con la participación de grupos de debate para llegar a un consenso sobre RSE y la aceptación de las eoloeléctricas en sus comunidades.

Por otro lado, Eléctrica del Valle de México, S. de R.L., por ser filial de EDF-energies nouvelles debería hacer suyas las políticas sobre RSE y hacer públicas sus aportes o iniciativas implementadas en la comunidad de Aguascalientes La Mata, en Asunción Ixtaltepec, Oax., y por supuesto identificar sus grupos de interés tanto primarios como secundarios para facilitar y promocionar la RSE.

\footnotetext{
4. Es una palabra que designa formas de cooperación, de trabajo en red entre el sector público, el sector privado, las organizaciones civiles, otras instituciones y sus stakeholders (Ministerio de Ambiente y Desarrollo Sostenible, 2018).
}

\section{Conclusiones}

La Responsabilidad Social Empresarial (RSE) y la Responsabilidad Social en las Administraciones (RSA) es un tema de importancia para el sector privado y público, México continúa siendo receptor de inversión extranjera directa, la presencia de multinacionales es constante, y esta inversión contribuye a la mejora de las condiciones sociales en el país, responsabilidad de las administraciones públicas. El diagnóstico a través de la metodología de la Agenda Desde lo Local identifica un gobierno municipal en condiciones no aceptables, es necesaria la propuesta de una unidad administrativa capaz de crear las condiciones para una proyección social interna y externa de la RSA, la gestión pública debe comprenderse con una perspectiva socialmente responsable. Asimismo, debe asumirse más allá de lo que establece la ley, contribuyendo a la solución de problemas sociales y ambientales. Entonces, de la misma manera que se exige a las empresas que cumplan con sus objetivos de manera responsable, se exige a las administraciones la obligación de promover, incentivar e impulsar la responsabilidad social y ejecutar acciones con una dimensión social responsable.

\section{Referencias}

Aguilar, L. F. (2010). Gobernanza: el nuevo proceso de gobernar. México: FCE.

Accountability. (2008). Norma de Aseguramiento de Sostenibilidad AA1000 AS (2008). London: Accountability, Recuperado de https://www. accountability.org/wp-content/uploads/2016/10/ AA1000AS_spanish.pdf

AENOR (2016). Extracto Norma Española UNE 66182. Madrid: AENOR. Recuperado de: https://www.aenor.es/aenor/descarga_extracto. asp?producto $=\mathrm{N} 0055991$

Administración General del Estado (AGE) (2012), "La responsabilidad social en la Administración General del Estado", en Memoria-informe sobre 
prácticas socialmente responsables, Madrid: Ministerio de Hacienda y Administraciones Públicas

Balaguer, M.; Fernández, M., \& Muñoz, M. (2007). La responsabilidad social de la empresa. Relaciones entre la performance social, financiera $y$ bursátil. Valencia: Generalitat.

Brugué, J. (2009). La responsabilidad social empresarial: una manifestación de lo que hoy llamamos gobernanza, en Administración Pública y RSC. Navarra: Gap-recursos.

Cueto, C.; \& De la Cuestas, M. (2017). Responsabilidad social en la administración pública y Modelo Europeo de Excelencia en la Gestión (EFQM). Madrid: Catedra Telefónica de Responsabilidad Corporativa y Sostenibilidad, UNED

Canyelles, J. (2011). Responsabilidad social de las administraciones públicas. en Revista de Contabilidad y Dirección, vol.13. 77-104. Recuperado de http://www.accid.org/revista/ documents/Responsabilidad_social_de_las_ administraciones_publicas.pdf

Consejo Nacional de la Cultura y las Artes. (2013). La Responsabilidad Social Empresarial y su aporte a la cultura. Chile: CNCA.

Cordero, J. (2018). El gobierno municipal ¿Promotor del desarrollo local? El caso del municipio semiurbano de $\mathrm{Cd}$. Ixtepec, Oaxaca. México: Estudios Sociales, Vol.28 (52). Julio-diciembre. Pp.1-29. DOI: http://dx.doi.org/10.24836/ es.v28i52.575

Cordero, J.M., González, J. \& Hernández N. (2014). Social Responsibility, Human Rights and Wind Energy: Oaxaca and Chiapas, Mexico: International Journal of Humanities and Social Science, 4(11). Pp. 45-53.

Del Pino, Alberto (2012). Modelo de responsabilidad social organizacional en la gestión pública, publicaciones técnicas 10. Argentina: Sindicatura General de la Nación (SIGEN).

Gaete, R. (2008). Aplicaciones de la responsabilidad social a la nueva gestión pública. Documentos y aportes en administración pública y gestión estatal. (11), julio-diciembre. 35-61.

INAFED-SG (2012). Programa Agenda Desde lo Local. México: INAFED-SG.

López, L. (Comp.) (2012). Globalización y agricultura. Nuevas perspectivas en la sociología rural. México: UAAAN-UA de C.

Lozano, J.; Albareda, Laura \& Tamyko, Ysea (2005). ¿Qué pueden hacer los gobiernos para promover la responsabilidad social de la empresa (RSE)?. Revista de Economía Pública, Social y Cooperativa. España: CIRIEC. Pp. 53-64.

Martínez, D. (2007). La responsabilidad social empresarial, el papel de los gobiernos, los organismos multilaterales y las $\mathrm{ONG}^{\prime}$ s. Documento de trabajo, México: Universidad Anáhuac.

Ministerio de Ambiente y Desarrollo Sostenible (2018). El Concepto de Partenariado. Recuperado de http://www.minambiente.gov.co/images/ AsuntosambientalesySectorialyUrbana/pdf/ Evaluaci\%C3\%B3n_Ambiental_Estrategica/ Concepto_de_Partenariado.pdf

Organización Internacional de Normalización (2010). Guia sobre responsabilidad social, Ginebra: Autor. Recuperado de www.foretica-org/biblioteca/...de.../259-borrador-final-de-la-iso-26000?

Porter, M. \& Kramer, M. (2006). Estrategia y sociedad: el vínculo entre ventaja competitiva y responsabilidad social corporativa: Harvard Business Review, 84(12).

Soria, D. (2014). La responsabilidad social pública. En documentos técnicos, xxiII Encuentro Anual de Administradores Fiscales. 
Teixidó, S., Chavarri, R., y Castro, A. (2002), Responsabilidadsocialempresarialen Chile:perspectivas para una matriz de análisis. Santiago: Fundación Prohumana. Recuperado de http://prohumana.cl/ documentos/documentoafrica2002.pdf

Tech4CDM (2009). La energía eólica en México. IDEA. Recuperado de http://www. tech4cdm.com/index.php/mod.pags/mem.detalle/ relcategoria.213/id.43

Vidal, I. (2012). El principio de valor compartido de Porter y Kramer. Revista ganar-ganar, Enerofebrero, (54). Recuperado de http://ganar-ganar. $\mathrm{mx} / \mathrm{pdf} / \mathrm{r} 54 / 26 . \mathrm{pdf}$

\section{Datos de filiación}

Jorge Martín Cordero Torres. Doctor en Gobierno y Administración Pública por la Escuela Libre de Ciencia Política y Administración Pública de Oriente. se desempeña como profesor investigador titular "A" adscrito al Departamento de Administración Pública de la Universidad del Istmo, campus Ixtepec, Oaxaca; México. Sus principales líneas de investigación son: desarrollo local y políticas públicas locales. Correo electrónico: j_cordero63@hotmail.com 